\title{
Early Metaphorical Communication: Farsi-Speaking Children Beginning to Learn Proverbs
}

\section{Seyyed-Abdolhamid Mirhosseini, Alzahra University, Iran}

\begin{abstract}
Dominant trends of studies on child language and communication have been traditionally concerned with early words and syntax. Little attention has been paid to the emergence of metaphorical and discursive aspects of child language. However, beyond the scope of formal linguistics and traditional cognitive psychology, nonliteral language use is an integral aspect of language acquisition that needs to be dealt with in child language research. This study explores the emergence of proverbs (as complex instances of nonliteral communication) in the language of 6 and 8-year-old Farsi speaking children in two primary schools in Tehran. It is observed that the participants' knowledge of common Farsi proverbs is beyond the expectations that may be hypothesized based on the existing thin body of literature on proverbs in children's communication. This relatively early emergence of proverbs in the language of Farsi speaking children and its possible interpretations are discussed in this article.
\end{abstract}

Keywords: metaphorical communication - first language learning - Farsi - proverbs 


\section{Introduction}

Classical accounts of first language learning and children's communication have been predominantly concerned with the emergence of words as well as early syntactic structures in child language. They have broadly tended to pay little, if any, attention to the development of metaphorical and discursive aspects of child language beyond sounds, words, and syntax. As a legacy of this classical trend, issues of discourse, pragmatics, and nonliteral meaning have continued to be only marginally considered in the mainstream research and theoretical debates in the broad field of child language development studies.

Traditionally, on the one hand, linguistically oriented approaches to child language, mainly influenced by Chomsky, generally focused on theoretical hypothesis making about child language development based on innatist views of language acquisition (Chomsky, 1980). Such orientations, famous for their out of context I-language view (Chomsky, 1986), put the development of syntactic combinations of the emerging lexical items at the center of their theorizations (Chomsky, 1969; Cook \& Newson, 1996; Smith, 1999). Almost no consideration of discursive aspects of language knowledge and use in social contexts is found in such Chomskyan accounts of language learning.

On the other hand, psychological studies of child language did not generally show interest in researching children's communication beyond early lexis and simple grammar. Accounts of language learning in psychology, unlike those within the Chomskyan trend, broadly considered the emerging language in its context of use but limiting the scope of their studies to the first two years of children's language development, they did not allow for tackling issues of discourse and pragmatics in later stages of child language learning (Richmond, 1970). By some more optimistic accounts, such psycholinguistic approaches since the 1960s have rarely gone beyond age 5 (Bates \& Goodman, 1999, cited in Berman, 2007). Moreover, prominently represented by Piaget, child language studies in the discipline of psychology have relied heavily on experimental research approaches (Beard, 1969) that may hardly lend themselves to the study of higher order aspects of language in its complex contexts of use.

More recently, researchers have started to recognize metaphorical and discursive aspects of the later stages in language learning as viable communication research issues and there has been growing interest in this area in the past three decades (e.g. Bates, 1976; Ervin-Tripp, et 
al., 1986; Ninio \& Snow, 1996; Loukusa, et al., 2007). As a clear example of this interest a special issue of Lingua has been recently devoted to language acquisition studies that move beyond the sentence and considers discourse (Kramer, 2007). Nonetheless, the area is still in its infancy and concerns for nonliteral and metaphorical considerations in child language studies continue to be in the margin and dominated by research on formal linguistic aspects of child language development. In the present study I have attempted to contribute to this intriguingly emerging research area through tackling the issue of learning proverbs by Farsi speaking children in the later stages of their language development. Understanding the emergence of proverbs as communicatively metaphorically complex phenomena with heavy metaphorical loads, may be illuminating as to the broader issues of nonliteral meaning, pragmatics, and discourse in later stages of child language learning.

\section{Theoretical Background}

\section{Non-Literal Child Language}

Despite the marginalization of research on 'later language development', as Nippold (1988) calls it, knowledge of language by some accounts continues to develop up to the age of 17 or even 19 (Karmiloff-Smith, 1992; Nippold, 1988). Learning various aspects of language knowledge and use, therefore, progresses well into adolescence, especially in terms of nonliteral language, meta-linguistic awareness, and discourse (Berman, 2007).

There is hardly any unified agreed upon definition of nonliteral and metaphorical aspects of child language and studies in these areas may focus on a diversity of issues. However, by stepping beyond formal properties of language, research on child language and communication "underscores the interrelationships between linguistic, cognitive, and pragmatic skills" (Bernicot, et al., 2007, p. 2115) in the emerging language of children. Taking this broad and rather loosely defined conception of nonliteral language acquisition, in this section a brief overview of some related studies are presented. Although the research trend founded on such metaphorical approaches may hardly be viewed as a major research stream in language acquisition research, the literature does include a number of studies on nonliteral aspects of child language. Of particular relevance to this study is the age related findings that try to specify age levels for acquiring aspects of nonliteral language comprehension and use. 
Children are able to engage in some forms of pragmatic processing as early as the age of 3 (Loukusa, et al. 2007) and this involves their ability to distinguish between what is said and what is meant, that is, literal and intended meaning (Berman, 2007; Lee, et al., 2001; Levorato \& Cacciari, 2002). In his recent book intriguingly titled 'From molecule to metaphor', Feldman (2009) refers to primary metaphor', stating that from early childhood children are able to engage with metaphors to "learn the vast range of interlinked concepts that constitute their culture" (p. 220). Of particular interest to researchers in the area of pragmatics and nonliteral meaning in child language learning and communication are issues of indirect requests, idioms, and implicature, among other topics.

An important issue in nonliteral language use is the understanding of indirect requests, which some researchers argue to be notable around the age of 5 to 6 (Elrod, 1987). Similar results were also presented by other researchers showing that indirect requests are understood by the age of 5 or even earlier (Bernicot, 1991). Later studies led by Bernicot found that French speaking children understood indirect requests at the age of 6 (Chaminaud, et al., 2006). It is widely acknowledged by many of the researchers in these areas that context plays an important role in understanding indirect requests (Loukusa, et al. 2007).

Idioms as stereotyped expressions with conventional non-stated meanings (Bernicot, et al. 2007; Gibbs, 1994) constitute another category of nonliteral language use studied in child language research (Ackerman, 1982). The characteristic feature of idioms is that their nonliteral meaning cannot necessarily be understood based on the literal meaning of their words. Research has shown that idioms are not understood by children before the age of 6 (Abkarian et al., 1992) and some studies found that 10-year-olds were able to understand idioms (Chaminaud, et al., 2006).

Another category of nonliteral language studied in the area of child language learning is implicature. Bernicot and colleagues (Bernicot, et al., 2007) have found that 6-year-olds understood semantic-inference implicatures but sarcastic-inference implicatures were not understood by children as old as 10 . Other studies suggested that children are able to answer questions related to implied meanings from the age of 7 onwards (Loukusa, et al. 2007). 
Berman (2007) reviews other aspects of nonliteral language studied within the context of first language acquisition, including narrative schema and making justifications. It is argued that children develop a narrative schema by 10 and understand discursive references to time, place, and participants. Children aged 8 to 12 are also claimed to be able to exploit complex linguistic as well as social skills in the processes of making justifications (Berman, 2007).

\section{Learning Proverbs}

Among reported studies of nonliteral aspects of child language learning, there is only very brief mentioning of learning proverbs (Gibbs, 2002). Even recent books dealing with details of conversational and metaphorical aspects of language acquisition do not seriously touch upon the proverb issue (Clark, 2009). The small number of studies that have been conducted on proverb understanding have mainly focused on adolescents. Some of these studies are situated within the realm of language acquisition and communication studies but others focus on aspects other than child language learning concerns, like speech pathology and hearing problems.

A quick overview of studies on proverb comprehension clearly indicates that the age range of the participants in these studies is well beyond the participant groups who are normally studied in child language acquisition research. The minimum age group of concern in these studies seems to be the age of 9 and the age range sometimes extends even beyond adolescence and into adulthood. Two early studies on proverb comprehension were carried out in the early 1980s. Kemper (1981) investigated understanding of proverbs in a series of studies using unfamiliar proverbs, finding out that the literal meaning of proverbs were understood more rapidly than their figurative meaning. Resnick (1982) studied the understanding of proverbs of different structural types by children aged 9 to 12 through both quantitative and qualitative research procedures.

A large body of research during the past 20 years has been conducted by Marilyn Nippold and her colleagues (Nippold, et al., 1988; Nippold, et al., 1998; Nippold, et al., 2000; Power, et al., 2001). Nippold, et al. (1988), mentioning the scarcity of the relevant body of research, question previous studies that highlighted the literal nature of proverb comprehension before adolescence, and maintained that the 10-year-old children are to perform well on proverb comprehension tasks that involve some contextual information. A decade later, another study 
(Nippold, et al., 1998) revealed that proverb comprehension ability grows during adolescence through to adulthood.

Later, Nippold, et al. (2000) studied 150 students at the age of 12, 15, and 18 with the aim of determining the association of their prior knowledge of the nouns in unfamiliar proverbs with their comprehension ability. They found word knowledge to be associated with proverb comprehension and their findings were claimed to support a model of adolescent proverb comprehension including both bottom-up and top-down processing. In another study by Nippold and colleagues participants aged 9,11 and 14 years completed comprehension tasks about literally true and literally false concrete proverbs (Power, et al., 2001). The results of the study are argued to be supporting the view that "figurative language is a direct, automatic and natural reflection of the way people think, reason and imagine" (p. 1).

More recently, Waldron, et al. (2007) explored the age related nature of proverb comprehension in a manner that dramatically highlights the complex, ongoing, and life-long nature of proverb learning. Aiming at the investigation of the extent to which proverb acquisition was age related, the researchers studied proverb comprehension of participants aged 20 to 80 . It was found out that the correct identification of common proverbs was notably a function of age, with participants in their sixties, seventies, and eighties having more correct responses than those in the twenties, thirties, and forties. Intriguing as the results are, the researchers found the results to be indications of the issue that proverbs represent a 'high form' of language use.

\section{The Study}

On the basis of the theoretical background briefly presented above, it is not easy to draw specific conclusions as to the starting age of learning proverbs by children. However, viewing proverb comprehension as a process resulting from "the gradual emergence of cognitive abilities reflected in a sequence of increasingly complex abilities" (Resnick, 1982, p. 521), it may be generally hypothesized that children only begin to learn nonliteral meanings of proverbs after the age of eight.

Therefore, the present study is specifically aimed at examining the hypothesis that 8-year-old Farsi speaking children are just beginning to learn proverbs and show meager indications of 
comprehending the non-literal meanings of common Farsi proverbs. Moreover, to chock this first hypothesis, 6-year-old children are expected to have almost no understanding of proverbs beyond the literal meaning of their constituting words. The study may shed light on the starting point of learning proverbs by Farsi speaking children and, more broadly, on their language socialization process.

\section{Participants}

The participants in this study are two groups of male Iranian children in two private educational institutes in Tehran. The first one is a group of 25 boys at the age of 6 who were randomly selected representatives of the 40 children in the two pre-school classes of their educational complex. The second group comprises 26 boys who are 8 years old and represent the 60 students in the two second grade classes of their primary school. Since access to the two target age groups at the same educational institute was not practically possible, the two groups of participants were selected from different places.

Both of these sites are prestigious educational institutes located in the north of Tehran and both the 6 and the 8-year-old participants of the study are from upper middle class families with the same socioeconomic status and the same level of cultural and educational family background. The 6-year-old participants were in their first year of semi-formal education in their pre-school classes and, therefore, were mostly illiterate. The group of 8-year-olds were in their early stages of literacy education in their first language.

\section{Instrument}

A special instrument was developed to examine the participants' knowledge of the topical content of proverbs. In order to develop the instrument, out of a pool of more than 1550 Farsi proverbs, about 100 common proverbs were selected by the researcher. These proverbs were further sieved and reduced to 50 with the aim of selecting the most commonly used proverbs in the daily conversations of speakers of Farsi. Out of the resulting set of proverbs, based on the judgment of three informants, 28 proverbs were finally selected as the ones that are part of the language knowledge of adult Farsi speaking people from almost all walks of life.

The selected set of proverbs were, therefore, viewed as integral parts of the knowledge of language that are almost certainly learnt by speakers of Farsi in the course of learning their 
mother tongue. On this basis, knowledge of these proverbs could be conveniently considered as part of the basic natural process of learning the mother tongue by all Farsi speaking children rather than a marked type of knowledge beyond the naturally occurring everyday communication.

The nonliteral topic of each one of the 28 selected proverbs was carefully considered and stated in a few words. For example the Farsi proverb Taa tanur garme nun ro bechasbun, literally saying Stick the bread while the oven is hot, refers to the idea of taking advantage of the opportunities that are available. Therefore, its nonliteral topical content was stated to be 'making use of opportunities'. As indicated in this example, the nonliteral topic is not related to the literal meaning of any of the words in the proverb. Another example is the proverb $T u$ haft aasemun ye setare nadaare which literally means $S /$ he has no star in the seven skies. The nonliteral topical content of this proverb was stated to be 'loneliness'.

Beside this stated topic that was based on the discursive aspect and the metaphorical dimension of the proverb meaning, alternative options needed to be developed to test the participant's knowledge of these proverbs. To reduce the chance effect in selecting the choice that reflected the meaning of the proverbs, for each one of them two topics were stated based on the literal meaning of the words included in the proverb. For example for the proverb $Y e$ dast seda nadare which literally means One hand has no sound, the comminicatively and metaphorically correct topic was stated as 'cooperation' and based on the literal meanings of the words hand and sound in the proverb the two alternative topical contents were stated as 'clapping' and 'making noise'.

Therefore, the resulting questionnaire included 28 proverbs along with three options for each one of them. One of the options stated the correct nonliteral topical content of the proverb and the other two merely reflected the literal meanings of the words stated in the proverb. The correct choice was randomly placed at each one of the three places of options for consecutive proverbs but overall 9, 9, and 10 correct choices were placed as the first, second, and third options respectively. 


\section{Procedure}

Examining learners' knowledge of nonliteral language can be carried out through two broad methodological approaches. The first one is assessing the knowledge of the participants through tapping their conversational skills in semi-natural contexts of language use (e.g. Fletcher, 1985). The second approach is relying on children's meta-pragmatic abilities, that is, their ability to describe their knowledge of the metaphorical and discursive aspects of language (Bernicot, 1991; Laval, 2003). These two broad approaches are usually considered as mutually exclusive methodologies and tend to be used separately (Bernicot, et al., 2007).

Within the context of the present research and considering the rather minor scope of this study investigating the participants' knowledge of proverbs in their real context of use was not practical. Moreover, relying on children's meta-pragmatic ability to fully describe their knowledge of the content and function of the proverbs is a problematic area (Bernicot, et al., 2007; Laval, 2003). Therefore, the adopted procedure in the present study is based on a midway approach between methodologies that consider context-based examination of nonliteral language acquisition and procedures that rely on learners' meta-pragmatic descriptions.

To translate this methodological approach into a practical data collection technique, the questionnaire-like data collection instrument described above was used. For each one of the proverbs, three choices were provided; two merely reflected the literal meaning of the words used in the proverb and one was based on their nonliteral meanings. The participants were asked to choose the option that in their view reflected the topic of the intended function of the proverb. The procedure did not target the depth of the participant's knowledge of proverbs but it was expected that reliable information be provided about their acquaintance with the nonliteral topical content and the general functioning of proverbs in communication.

Since the group of 6-year-old children were not literate and the 8-year-old participants were not able to independently read the proverbs and choices comfortably, the questionnaire-like instrument containing the proverbs and the triple choices had to be administered orally by the researcher. The process was introduces to the participants as a game called the proverbs game' that required them to listen carefully and choose the option that best reflected the meaning of the proverb in their view. Each proverb was read out by the researcher and the participants were asked to choose if it was about the first, second, or third choice. 


\section{Findings and Analysis}

For each one of the proverbs each student decided if it was about the first, second, or third choice. In some cases the students were not able to decide which one of the proverbs was about. These cases along with the incorrect choices were together considered as shaping the incorrect response frequency since both incorrect responses and indecision indicated lack of knowledge of the proverb. Table 1 presents the frequency of correct as well as incorrect responses of the 25 pre-school children aged 6 for each one of the 28 proverbs.

Table 1. Frequencies of responses of 6-year-old children

\begin{tabular}{|c|c|c|c|c|c|}
\hline $\begin{array}{l}\text { Prov. } \\
\text { No. }\end{array}$ & $\begin{array}{l}\text { Frequency } \\
\text { of Correct } \\
\text { Responses }\end{array}$ & $\begin{array}{l}\text { Frequency } \\
\text { of Incorrect } \\
\text { Responses }\end{array}$ & $\begin{array}{l}\text { Prov. } \\
\text { No. }\end{array}$ & $\begin{array}{l}\text { Frequency } \\
\text { of Correct } \\
\text { Responses }\end{array}$ & $\begin{array}{l}\text { Frequency } \\
\text { of Incorrect } \\
\text { Responses }\end{array}$ \\
\hline $\mathbf{1}$ & 8 & 17 & $\mathbf{1 5}$ & 20 & 5 \\
\hline $\mathbf{2}$ & 18 & 7 & $\mathbf{1 6}$ & 13 & 12 \\
\hline $\mathbf{3}$ & 7 & 18 & $\mathbf{1 7}$ & 4 & 21 \\
\hline $\mathbf{4}$ & 7 & 18 & $\mathbf{1 8}$ & 10 & 15 \\
\hline $\mathbf{5}$ & 8 & 17 & $\mathbf{1 9}$ & 1 & 24 \\
\hline $\mathbf{6}$ & 6 & 19 & $\mathbf{2 0}$ & 9 & 16 \\
\hline $\mathbf{7}$ & 7 & 18 & $\mathbf{2 1}$ & 4 & 21 \\
\hline $\mathbf{8}$ & 18 & 7 & $\mathbf{2 2}$ & 6 & 19 \\
\hline $\mathbf{9}$ & 1 & 24 & $\mathbf{2 3}$ & 13 & 12 \\
\hline $\mathbf{1 0}$ & 5 & 20 & $\mathbf{2 4}$ & 14 & 11 \\
\hline $\mathbf{1 1}$ & 7 & 18 & $\mathbf{2 5}$ & 3 & 22 \\
\hline $\mathbf{1 2}$ & 1 & 24 & $\mathbf{2 6}$ & 8 & 17 \\
\hline $\mathbf{1 3}$ & 15 & 10 & $\mathbf{2 7}$ & 9 & 16 \\
\hline $\mathbf{1 4}$ & 4 & 21 & $\mathbf{2 8}$ & 9 & 16 \\
\hline
\end{tabular}

Table 2 presents the frequency of correct as well as incorrect responses of the 26 second grade students aged 8 for each one of the 28 proverbs. A quick comparison of the frequency of correct responses of this table with Table 1 indicates that unlike the first group, the children in this second group show a high level of acquaintance with the functional topics of the proverbs. While the 6-year-olds are just beginning to learn proverbs, the 8-year-olds children are largely familiar with the most common proverbs in their mother tongue and have already well progressed in acquiring the pragmatic and metaphorical aspects language in their communication. 
Online Journal of Communication and Media Technologies

Volume: 7 - Issue: 1 January - 2017

Table 2. Frequencies of responses of 8-year-old children

\begin{tabular}{|l|c|c|c|c|c|}
\hline $\begin{array}{l}\text { Prov. } \\
\text { No. }\end{array}$ & $\begin{array}{l}\text { Frequency } \\
\text { of Correct } \\
\text { Responses }\end{array}$ & $\begin{array}{l}\text { Frequency } \\
\text { of Incorrect } \\
\text { Responses }\end{array}$ & $\begin{array}{l}\text { Prov. } \\
\text { No. }\end{array}$ & $\begin{array}{l}\text { Frequency } \\
\text { of Correct } \\
\text { Responses }\end{array}$ & $\begin{array}{l}\text { Frequency } \\
\text { of Incorrect } \\
\text { Responses }\end{array}$ \\
\hline $\mathbf{1}$ & 26 & 0 & $\mathbf{1 5}$ & 26 & 0 \\
\hline $\mathbf{2}$ & 26 & 0 & $\mathbf{1 6}$ & 18 & 8 \\
\hline $\mathbf{3}$ & 12 & 14 & $\mathbf{1 7}$ & 24 & 2 \\
\hline $\mathbf{4}$ & 23 & 3 & $\mathbf{1 8}$ & 24 & 2 \\
\hline $\mathbf{5}$ & 24 & 2 & $\mathbf{1 9}$ & 13 & 13 \\
\hline $\mathbf{6}$ & 24 & 2 & $\mathbf{2 0}$ & 23 & 3 \\
\hline $\mathbf{7}$ & 23 & 3 & $\mathbf{2 1}$ & 24 & 2 \\
\hline $\mathbf{8}$ & 25 & 1 & $\mathbf{2 2}$ & 23 & 3 \\
\hline $\mathbf{9}$ & 20 & 6 & $\mathbf{2 3}$ & 24 & 2 \\
\hline $\mathbf{1 0}$ & 21 & 5 & $\mathbf{2 4}$ & 23 & 3 \\
\hline $\mathbf{1 1}$ & 19 & 7 & $\mathbf{2 5}$ & 24 & 2 \\
\hline $\mathbf{1 2}$ & 18 & 8 & $\mathbf{2 6}$ & 22 & 4 \\
\hline $\mathbf{1 3}$ & 26 & 0 & $\mathbf{2 7}$ & 23 & 3 \\
\hline $\mathbf{1 4}$ & 26 & 0 & $\mathbf{2 8}$ & 14 & 12 \\
\hline
\end{tabular}

For a more accurate measure of the differences between the two groups Pearson Chi-Square Test was run on SPSS 13 and the two groups appeared to have performed with a significant difference in their correct response frequencies at 0.05 level of significance. The difference in the performance of the groups of participants is graphically illustrated in Graph 1.

Graph 1. Frequencies of correct responses by the two groups

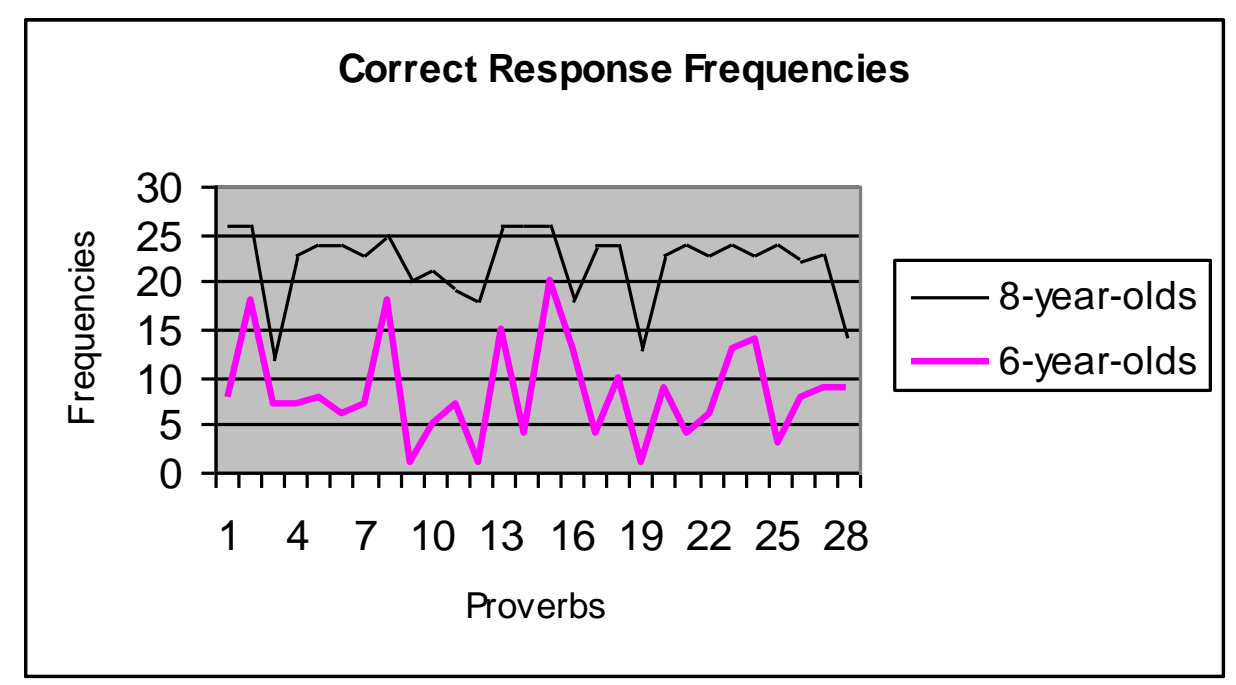

\section{Discussion and Conclusion}

The existing body of literature on child language and communication generally suggests that early metaphorical understanding appears not sooner that the age of three (Loukusa, et al. 
2007). Depending on the complexity of the nonliteral aspect of language use varying age thresholds are suggested by studies in this area:

Indirect requests are argued to be understandable at around 5 to 6 (Bernicot, 1991; Elrod, 1987; Chaminaud, et al., 2006); different types of implicature were found to be understandable by children at 6 and sometimes up to 10 (Bernicot, et al., 2007; Loukusa, et al. 2007); and from the age of six, children were observed to be able to start recognizing idioms and it was some times estimated that children should be about 10 before they are able to fully entertain idioms (Abkarian et al., 1992; Chaminaud, et al., 2006). More complex discursive issues, including proverb comprehension, are believed to appear in children's communication from this age on.

As specifically concerned with proverbs, the literature broadly seems to show a consensus that proverbs are among the most complicated language function categories (Clark, 2009; Gibbs, 2002; Nippold, et al., 1988; Nippold, et al., 1998; Nippold, et al., 2000). Therefore, with a consideration of all the metaphorical complexities involved in interpreting proverbs and based on the existing thin body of literature on the issue, the hypothesized expectation in this study was that 6-year-old children are not able understand proverbs beyond the literal meaning of words. In accordance with the existing literature, it was also expected that 8-yearold Farsi speaking children show just very early signs of comprehending proverbs and with little indications of understanding the complex pragmatic functioning of proverbs.

However, despite the hypothesized expectations the results of this study, as presented in the previous section, clearly indicated that 6-year-old Farsi speaking children are already well on their way of acquiring proverbs. Although they are far from full comprehension of proverbs, the frequency of their correct responses as, shown in Tables 1, indicates that they are quite familiar with the metaphorical functioning of language use that involves nonliteral meaning and goes beyond the surface level semantic aspect of words and phrases.

Moreover, 8-year-old children are depicted by the literature as the age group just stepping into the stage of beginning to learn non-literal meaning and metaphorical functioning of proverbs. Nonetheless, the 8-yaer-old Farsi speaking children participating in this study 
appear to be fully aware of the non literal functioning of proverbs and to be almost fully able to understand common Farsi proverbs.

These findings are clearly questioning the existing views on early understanding of first language proverbs based on studies that have been conducted on languages such as English, French, and Finnish (Chaminaud, et al., 2006; Kemper, 1981; Loukusa, et al., 2007; Resnick, 1982; Nippold, et al., 1988; Nippold, et al., 1998; Nippold, et al., 2000; Power, et al., 2001). It is not easy to interpret the results of this study and why they are not supporting the trends reported in the literature based on previous studies of non-literal meaning in child language learning. However, a viable conjecture may be broadly made about possible roots of such mismatch and for the observed tendency of Farsi speaking children to begin proverb learning and metaphorical communication sooner than children speaking other first languages.

Interpersonal relationships within the community of Iran have been traditionally based on intimate ties rooted in the long history and exceptionally rich culture of its people. One of the observable aspects of the diverse historical experiences and the cultural heritage of the Farsi speaking people is reflected in the large number and the wide topic range of Farsi proverbs, many of which are part of people's everyday language. The relatively early acquisition of proverbs by Farsi speaking children may well be related to this cultural and social context and to the very poetic nature of everyday Farsi that children are exposed to. It might be argued that the inherent poetic nature of the Farsi language (relatively more considerable than languages like Finnish and English) is the reason why Farsi speaking children start learning proverbs sooner than children speaking those languages.

This case, however, could not be made very strongly because of the limited scope of the current research. The specific social, economic, and even geographical scope of research makes it difficult to draw conclusions about the emerging patterns of proverbs in the language of Farsi speaking children that are of extremely diverse in terms of local, sociocultural, and economic contexts. Moreover, the mere one-shot frequency data can not be safely relied upon as strongly dependable evidence with regard to the nature of the emergence of proverbs. More qualitative in depth studies are required, including the ones relying on interviews that may help child language and communication researchers understand children's perceptions of different aspects of proverbs and nonliteral language use in general. 


\section{References}

Resnick, D. A. (1982). A developmental study of proverb comprehension. Journal of Psycholinguistic Research, 11(5): 521-538.

Abkarian, G. G., Jones, A., \& West, G. (1992). Young children's idiom comprehension: trying to get the picture. Journal of Speech and Hearing Research 35: 580-587.

Ackerman, B. P. (1982). On comprehending idioms: Do children get the picture? Journal of Experimental Child Psychology, 33(3): 439-454.

Bates, E. (1976). Language and context: The acquisition of pragmatics. Academic Press, New York.

Beard, R. M. (1969). An outline of Piaget's developmental psychology for students and teachers. London: Routledge \& Kegan Paul.

Berman, R. A. (2007). Developing linguistic knowledge and language use across adolescence. In E. Hoff \& M. Shatz (Eds.), Blackwell handbook of language development (pp. 347-367). Oxford: Blackwell.

Bernicot, J. (1991). French children's conception of requesting: the development of metapragmatic knowledge. International Journal of Behavioral Development, 14: 285-304.

Bernicot, J., Laval, V., \& Chaminaud, S. (2007). Nonliteral language forms in children: In what order are they acquired in pragmatics and metapragmatics? Journal of Pragmatics, 39: 2115-2132.

Chaminaud, S., Laval, V., \& Bernicot, J. (2006). Pragmatics and language comprehension in children: A study of nonliteral forms using a computerized paradigm. Annee Psychologique, 106: 491-512.

Chomsky, N. (1969). The acquisition of syntax in children from 5 to 10. Cambridge, MA: MIT press.

Chomsky, N. (1980). Rules and representations. Oxford: Basil Blackwell.

Chomsky, N. (1986). Knowledge of language: Its nature, origin and use. New York: Praeger.

Clark, E. C. (2009). First language acquisition (2nd ed.).Cambridge: Cambridge University Press.

Cook, V. J. \& Newson, M. (1996). Chomsky's universal grammar (2nd ed.). Oxford: Blackwell.

Elrod, M. M. (1987). Children's understanding of indirect request. Journal of Genetic Psychology, 148(1): 63-70. 
Ervin-Tripp, S., Strage, A., Lampert, M., \& Bell, N. (1986). Understanding requests. Linguistics, 25: 107-143.

Feldman, J. A. (2009). From molecule to metaphor: A neural theory of language. Cambridge, MA: The MIT Press.

Gibbs Jr., R. W. (1994). The poetics of mind: Figurative thought, language and understanding. Cambridge: Cambridge University Press.

Gibbs Jr., R. W. (2002). A new look at literal meaning in understanding what is said and implicated. Journal of Pragmatics, 34: 457-486.

Karmiloff-Smith, A. (1992). Beyond modularity: A developmental perspective on cognitive science. Cambridge, MA: MIT Press.

Kemper, S. (1981). Comprehension and the interpretation of proverbs. Journal of Psycholinguistic Research, 10(2): 179-198.

Kramer, I. (2007). Language acquisition between sentence and discourse: Editorial. Lingua, 117: 1833-1836.

Laval, V. (2003). Idiom comprehension and metapragmatic knowledge in French children. Journal of Pragmatics, 35: 723-739.

Lee, E., Torrance, N., \& Olson, D. (2001). Young children and the say/mean distinction:Verbatim and paraphrasing recognition in narrative and nursery rhyme contexts. Journal of Child Language, 28: 531-543.

Levorato, M., \& Cacciari, C. (2002). The creation of new figurative expressions: Psycholinguistics evidence in Italian children, adolescents and adults. Journal of Child Language, 20: 127-150.

Loukusa, S., Leinonen, E., \& Ryder, N. (2007). Development of pragmatic language comprehension in Finnish-speaking children. First Language 27(3): 279-296.

Ninio, A. \& Snow, C. (1996). Pragmatic development. Westview Press, Colorado.

Nippold, M. A. (Ed.). (1988). Later language development: Ages nine through nineteen. Austin, TX: Pro-Ed.

Nippold, M. A., Allen, M. M., \& Kirsch, D. I. (2000). How adolescents comprehend unfamiliar proverbs: The role of top-down and bottom-up processes. Journal of Speech, Language, and Hearing Research, 43: 621-630.

Nippold, M. A., Hegel, S. L., Uhden, L. D., \& Bustamante, S. (1998). Development of proverb comprehension in adolescents: Implications for instruction. Communication Disorders Quarterly, 19(2): 49-55. 
Nippold, M. A., Martin, S. A., \& Erskine, B. J. (1988). Proverb comprehension in context: A developmental study with children and adolescents. Journal of Speech and Hearing Research, 31: 19-28.

Power, R., Taylor, C. L., \& Nippold, M. A. (2001). Comprehending literally-true versus literally-false proverbs. Child Language Teaching and Therapy, 17(1): 1-18.

Richmond, P. G. (1970). An introduction to Piaget. London: Routledge \& Kegan Paul.

Smith, N. (1999). Chomsky: Ideas and ideals. Cambridge: Cambridge University Press.

Waldron, N., Johnston, R., \& Hull, R. (2007, November). Knowledge of proverbs as a function of age. Paper presented at the American Speech-Language-Hearing Association Annual National Convention, Boston, MA. 